\title{
ASSESSMENT OF SHOULDER
}

AND LOW BACK MUSCLE ACTIVITY

OF MALE KITCHEN WORKERS

USING SURFACE ELECTROMYOGRAPHY

\section{SHANKAR SUBRAMANIAM ${ }^{1}$, SHANMUGAM MURUGESAN² ${ }^{2}$, and SRINIVASAN JAYARAMAN ${ }^{3}$}

${ }^{1}$ Kongu Engineering College, Perundurai, Tamil Nadu, India

Department of Mechatronics Engineering

${ }^{2}$ Saveetha Engineering College, Chennai, Tamil Nadu, India

Department of Mechanical Engineering

${ }^{3}$ University of Quebec, Montreal, Quebec, Canada

National Institute of Scientific Research, Energy Materials Telecommunications Research Centre

\begin{abstract}
Objectives: This study aims to assess muscle fatigue for kitchen workers during various tasks in a kitchen. Material and Methods: This study consists of 2 phases: a) surface electromyography (EMG) to determine muscle fatigue of trapezius and erector spinae muscles bilaterally for 12 healthy male volunteers during $30 \mathrm{~min}$ of Indian flatbread (chapati) preparation, b) self-administered questionnaire study after 30 min preparation to determine the impact on performance. Results: Surface EMG results show that the right trapezius muscle had significantly higher fatigue during kneading, rolling and roasting tasks. Similarly, right erector spinae muscle showed significantly higher fatigue during rolling and roasting tasks. Conclusions: Both phases of the study conclude that, even though the dynamic postural adjustment may reduce fatigue during the work schedule; the combination of risk factors like the repetitive task, forceful exertion and prolonged standing during working results in a high risk of developing muscle fatigue. Int J Occup Med Environ Health 2018;31(1):81-90
\end{abstract}

Key words:

Low back pain, Shoulder pain, Muscle fatigue, Surface EMG, Kitchen workers, Musculoskeletal disorder

\section{INTRODUCTION}

Cooking is a part of day-to-day activity for an individual to lead a life. However, as a profession like an institute kitchen worker, they prepare a wide range of foods and recipes in routine manner. Institutional kitchens are equipped with modern equipment, convenient work areas, and perfect air conditioning. Still preparation of food for the large number of students within predetermined time causes huge workload and pressure to the kitchen workers. Thereby kitchen work includes physical and psychosocial load factors and the employees have plenty of musculoskeletal problems [1]. The work nature of the kitchen workers generally means long standing hours, constant leaning

Received: January 25, 2016. Accepted: November 9, 2016.

Corresponding author: S. Subramaniam, Kongu Engineering College, Department of Mechatronics Engineering, Thoppupalayam, Perundurai, Tamil Nadu 638060, India (e-mail: shankariitm@gmail.com). 
forward posture and repetitive motion in the upper limbs [2].

Collins et al. [3] have reported that risk factors associated with the development of work-related musculoskeletal disorders (WMSD) include repetition hand movement, static work postures and forceful exertion. Furthermore, Gigstad [4] reports that repetition of an activity over long periods may lead to fatigue and muscle-tendon strain. In addition, Ono et al. [2] report that higher prevalence of musculoskeletal disorders occurs for cooks rather than for other occupational workers. On the other hand, various research studies on occupational risks and risk factors in food industry workers have reported a higher prevalence of musculoskeletal disorder (MSD) symptoms in the neck, shoulders, and low back. In the case of kitchen workers, MSDs have been observed among commercial food service workers who perform repetitive monotonous tasks [5,6].

Accordingly, it has been reported that low back pain (LBP) among cooks has become a major source of occupational health problems [7]. Low back pain may be due to prolonged forward flexion or leaning since the posterior annulus may develop accumulated microdamage [8]. Work involving prolonged static postures may be a significant risk factor for WMSDs [9]. Potential risk factors for upper extremity, low back and lower extremity have been found predominantly in the case of kitchen work [10].

The sustained muscular contractions externally associated with muscle, that will not be able to maintain a certain force, lead to physiological fatigue, tremor or pain, localized in the specific muscle. This is called muscular fatigue [11]. Surface electromyography (sEMG) is the most popular approach for measuring muscle activation and fatigue. Feasible and reliable means of assessing muscle fatigue in ergonomic studies include the analysis of sEMG recordings and development of a pattern for the muscle action potential [12] changes in the sEMG activ-

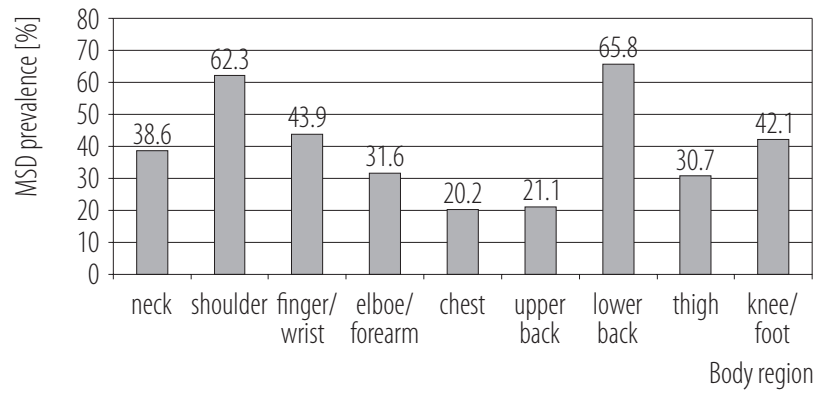

Fig. 1. Musculoskeletal disorders (MSD) among male kitchen workers $(\mathrm{N}=12)$ during various tasks in the kitchen

ity (decrease in the mean power frequency (MPF) and/ or increase in the sEMG amplitude) during standardized voluntary contractions, and are frequently used as indicators of muscle fatigue [8].

Our previous studies on kitchen workers are in line with several findings. It has been stated that the result of the Nordic Musculoskeletal Questionnaire (NMQ) survey among 114 male kitchen workers indicates 67.5\% of MSDs during the past 12 months [13,14]. The highest prevalence rate of MSD is for the lower back (65.8\%), shoulder region $(62.3 \%)$ and followed by finger/ wrist (43.9\%), knee/foot (42.1\%), neck region (38.6\%), elbow/forearm (31.6\%), thigh (30.7\%), upper back (21.1\%), and chest $(20.2 \%)$, respectively as shown in the Figure 1. On the other hand, the study results infer that Indian flatbread preparation is a more risky task than the other tasks like preparation of dosa and preparation of rice in the case of Indian kitchen work [13,14].

The findings have served the grounds for assessing the muscle activity on the low back and shoulder region among institutional kitchen workers in south India during their various tasks such as Indian flatbread (chapati) preparation. In this study, various risk factors and highly discomfort body regions have been identified during allotted tasks. In summary, one could infer that institute kitchen workers experience higher fatigue, even though they adapt a dynamic posture during their work schedule. 


\section{MATERIAL AND METHODS}

\section{Experimental model}

\section{Experimental protocol}

In this study, participants were divided into 4 groups equally and a selected task was assigned to each group:

- group 1 - kneading task,

- group 2 - slicing task,

- group 3 - rolling task,

- group 4 - roasting task.

Each group was instructed to perform their tasks for the duration of $30 \mathrm{~min}$. Subjects were allowed to make adjustments to body posture in order to maintain comfort and they were not allowed to take walking breaks. Kneading task was the first step in the preparation of Indian flatbread (chapati) - it is the process of mixing wheat flour with water as shown in the Photo 1 . After kneading, it was kept separately for $2 \mathrm{~h}$ for better flexibility and easy rolling. Then it was sliced into small pieces for rolling into flat as shown in the Photo 2. Rolling task means rolling the sliced pieces into a flat bread using rollers as shown in the Photo 3. Finally the rolled flat bread gets roasted in heated metal plate gas stoves as shown in the Photo 4.

Subjects were requested not to undergo any heavy training or physical activities $24 \mathrm{~h}$ prior to the experiment. All the subjects were right-hand dominant and they had not

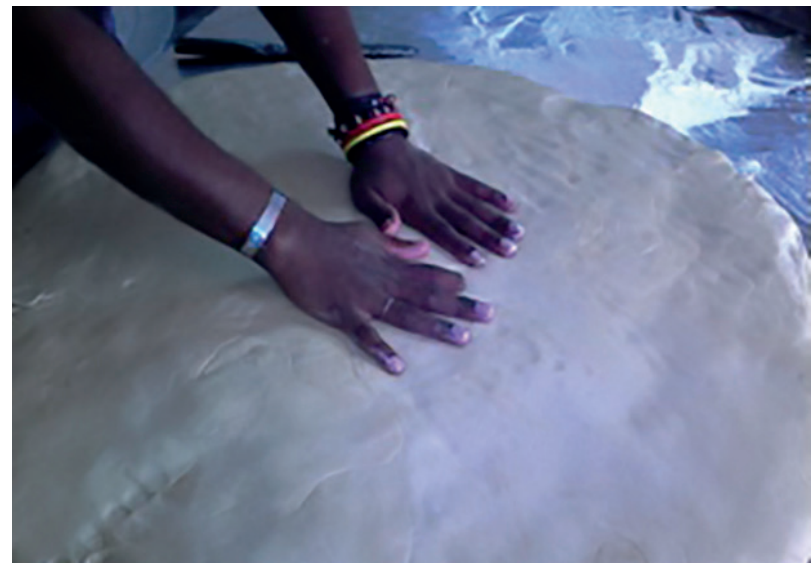

Photo 1. Kneading task performed by male kitchen workers (group 1)

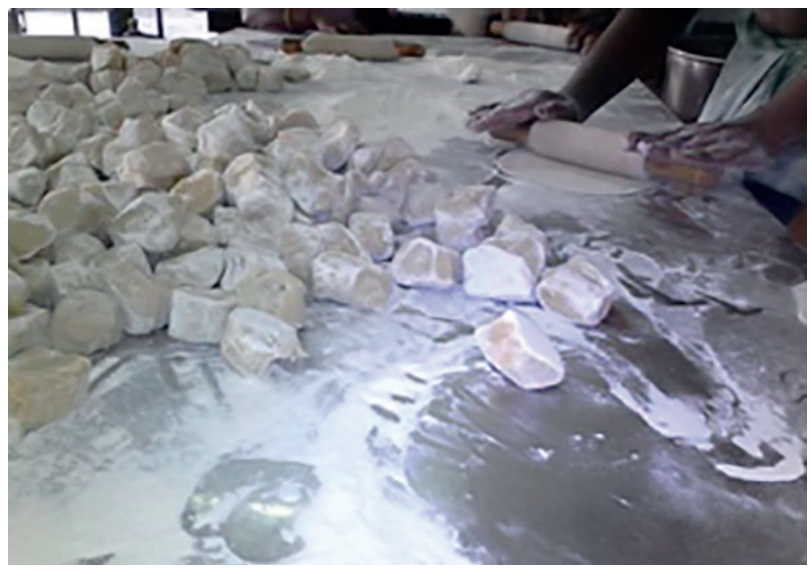

Photo 2. Slicing task performed by male kitchen workers (group 2)

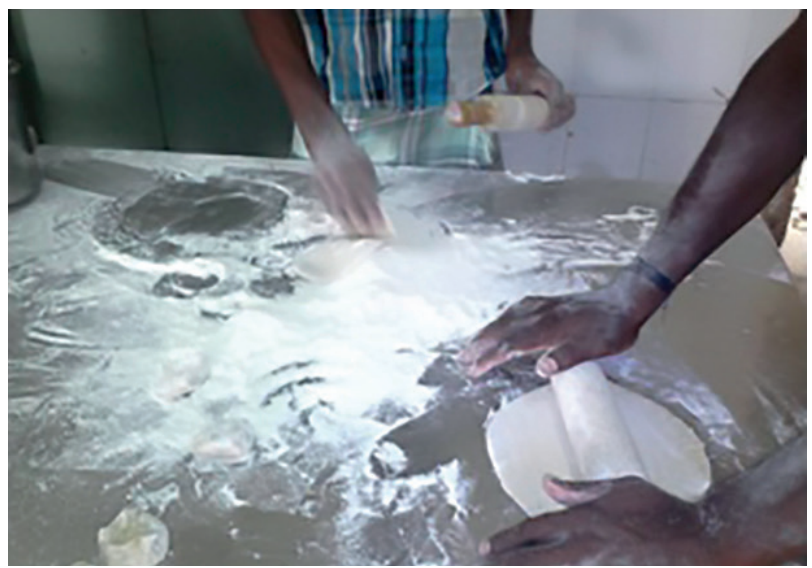

Photo 3. Rolling task performed by male kitchen workers (group 3)

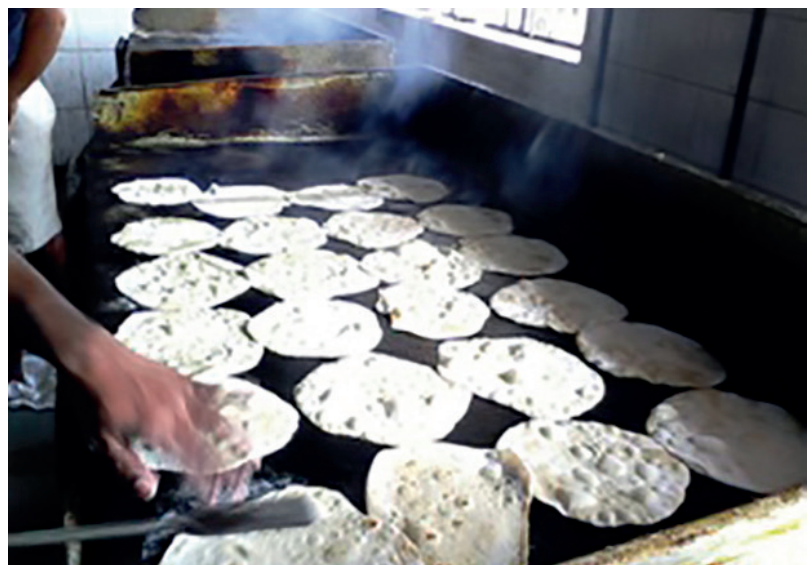

Photo 4. Roasting task performed by male kitchen workers (group 4) 
had any history of illness or disorders in shoulder or low back. All the subjects had been made fully aware of the experimental details and signed informed consents that were obtained as approved by the ethical guideline of Kongu Institutions, Tamil Nadu, India.

\section{Subjects}

The study group consisted of 12 healthy male kitchen workers recruited from institutional kitchens located in the western part of the state of Tamil Nadu, India. The subjects had mean experience of 7.8 years in the kitchen industry, aged 19-24 years old (mean $(\mathrm{M})=21.5$ years); weighed $55-80 \mathrm{~kg}(\mathrm{M}=63.6 \mathrm{~kg})$ and height $165-173 \mathrm{~cm}$ $(\mathrm{M}=168.9 \mathrm{~cm})$. Notably, the participated subjects did not smoke and were not habituated towards consuming alcohol.

\section{Electrode placement}

In this study, trapezius and erector spinae muscle group was considered bilaterally and electrodes were placed as shown in the Figure 2. Care was taken for placing the electrodes on the targeted muscles. Before placement of the electrode, the skin was prepared by cleaning the site with water, abraded with sandpaper (shaved if necessary) and cleaned with ethanol gel to avoid impedance mismatch and movement artifact. After preparation of the skin, self-adhesive silver/ silver chloride $(\mathrm{Ag} / \mathrm{AgCl})$ electrodes were placed at trapezius and erector spinae muscles to acquire muscle activity.

\section{Data acquisition}

Surface EMG signals were recorded at a sampling frequency of $1000 \mathrm{~Hz}$ using a sEMG system (Skrip electronics-EMG-02, India). Data acquisition was done with the customized program in LabVIEW ${ }^{\mathrm{TM}}$ (National Instruments, Inc.). Surface electromyography results were collected at 3 intervals for all the subjects during the $30 \mathrm{~min}$ of total duration of the experiment. The 3 intervals were:

- before the individual task (baseline reading),

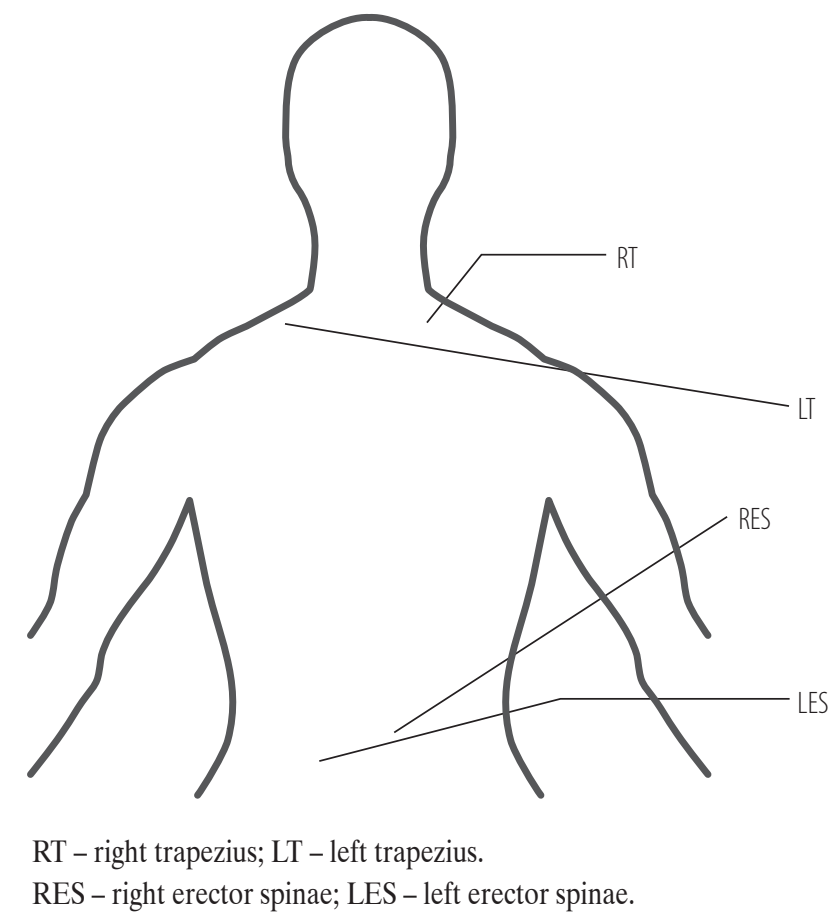

Fig. 2. Electrode placement, targeted muscles of male kitchen workers $(\mathrm{N}=12)$ during various tasks in the kitchen

- 15 th min of task,

- 30th min of the individual task of Indian flatbread preparation.

Surface electromyography signals were recorded for the duration of $10 \mathrm{~s}$, during each of individual Indian flatbread preparation tasks using the National Instrument's DAQ card-6221.

\section{Analysis}

Raw sEMG was filtered using a second order Butterworth filter with a pass band of $20-450 \mathrm{~Hz}$ and notch filter with a band stop of $50 \mathrm{~Hz}$ was used for eliminating alternating current $(\mathrm{AC})$ line interference. Filtered signals were normalized with respect to mean, and then full-wave rectified.

The influence of muscle fatigue was studied by assessing the frequency domain power spectrum of sEMG $[8,15]$. The power spectrum of the sEMG was reported to change under the influence of muscle fatigue [16]. There was an 
increase in the amplitude of the lower frequency band and a relative decrease in higher frequency band. The decrease in mean power frequency (MPF) from sEMG profiles is a recognized method of determining fatigue in an isometric muscle action [8]. In this study, hamming windowed-based power spectral analysis was performed on the rectified signal to extract the MPF. Thus extracted MPF was used as feature parameters for determining the muscle fatigue. Signal processing was done using MATLAB ${ }^{\mathrm{TM}}$ software package. Furthermore, the fatigue difference was calculated using MPF difference as given in the equation below [17]. It was used for determining the level of muscle fatigue:

$$
\text { MPF difference }=\left(\mathrm{MPF}_{\text {after }}-\mathrm{MPF}_{\text {before }}\right)
$$

where:

MPF - mean power frequency.

\section{Statistical analysis}

The mean power frequency parameter determined from the acquired sEMG signals was statistically analyzed to determine the significant difference $(p<0.05)$ among tasks. Feature parameters were tested for normality and skewness result yielded a negative result; hence a nonparametric test of Friedman test was performed on the features to determine the level of significance of muscle activity. In addition, the post hoc analysis was performed using the Tukey multiple comparisons test to determine the population size with the confident interval of $91 \%$. All the statistical analyses were carried out using the statistical package for social sciences (SPSS version 20.0).

\section{Psychophysical test: evaluating the prevalence (\%)}

\section{of upper extremity pain and discomfort}

\section{for flatbread task in the kitchen}

The self-administered questionnaire study was conducted among all the subjects to rate the discomfort level immediately after 30 min of the task completion. Psychophysi- cal tests involving questionnaire studies are well-known valid methodologies for screening MSD [18-20]. The visual analog scale was used for quantifying the overall discomfort levels in various anatomical sites and the mean values were corroborated with the sEMG findings after the experiment.

\section{RESULTS}

\section{sEMG experimental model}

Surface EMG results for the kitchen work during rolling and roasting task show a steady MPF decrease; that indicates an increase in muscle fatigue. In particular, the MPF value of right trapezius muscle shows a significant difference $(p<0.05)$ for all 3 tasks except for the slicing task. The Table 1 shows the mean MPF difference and standard deviation values of trapezius and erector spinae muscle for various groups. The Figure 3 shows the MPF difference between the 4 groups of right trapezius muscle. Furthermore, Friedman test result shows that the slopes of both root mean square (RMS) and MPF vs. time reveal a significant difference $(\mathrm{p}<0.05)$ between group 3 and group 1 for right trapezius muscle.

Accordingly, the right erector spinae muscle group shows a significant difference during the rolling and roasting task. There was a significant positive rate of change in RMS with the concomitant negative change of MPF in the right erector spinae and right trapezius muscle of groups 3 and 4 . The Figure 4 shows the mean and standard error values of MPF difference of the right erector spinae. However, the result shows that during the entire $30 \mathrm{~min}$ of the slicing task, there was no statistical difference for the left trapezius and erector spinae muscle group.

\section{Psychophysical test: evaluation of prevalence (\%) of upper extremity MSD during Indian flatbread preparation task for kitchen workers}

Furthermore, in order to determine and quantify the severity of body pain and discomfort the individuals were admitted 
Table 1. Mean power frequency (MPF) of trapezius and erector spinae muscle for male kitchen workers $(\mathrm{N}=12)$ during various tasks

\begin{tabular}{|c|c|c|c|c|c|}
\hline \multirow{2}{*}{ Muscle } & \multicolumn{5}{|c|}{$\begin{array}{c}\mathrm{MPF} \\
(\mathrm{M} \pm \mathrm{SD})\end{array}$} \\
\hline & $\begin{array}{l}\text { group } 1 \\
(\mathrm{~N}=3)\end{array}$ & $\begin{array}{l}\text { group 2 } \\
(\mathrm{N}=3)\end{array}$ & $\begin{array}{l}\text { group } 3 \\
(\mathrm{~N}=3)\end{array}$ & $\begin{array}{l}\text { group } 4 \\
(\mathrm{~N}=3)\end{array}$ & $\begin{array}{c}\text { total } \\
(\mathrm{N}=12)\end{array}$ \\
\hline \multicolumn{6}{|l|}{ Trapezius } \\
\hline left & $4.21 \pm 3.43$ & $10.16 \pm 13.23$ & $-10.03 \pm 7.21$ & $0.67 \pm 7.33$ & $1.25 \pm 7.80$ \\
\hline right & $-10.62 \pm 9.58^{*}$ & $2.31 \pm 9.11^{*}$ & $-15.21 \pm 3.54^{*}$ & $-3.2 \pm 9.62^{*}$ & $-6.68 \pm 7.96^{*}$ \\
\hline \multicolumn{6}{|l|}{ Erector spinae } \\
\hline left & $5.72 \pm 2.57$ & $11.27 \pm 2.23$ & $-6.33 \pm 9.22$ & $5.67 \pm 5.93$ & $4.08 \pm 4.98$ \\
\hline right & $1.08 \pm 3.43^{*}$ & $8.64 \pm 3.54^{*}$ & $-9.45 \pm 11.89^{*}$ & $-4.15 \pm 2.61^{*}$ & $-0.97 \pm 5.36^{*}$ \\
\hline
\end{tabular}

$\mathrm{M}$ - mean; SD - standard deviation.

Group: 1 - kneading task, 2 - slicing task, 3 - rolling task, 4 - roasting task.

$* \mathrm{p}<0.05$.

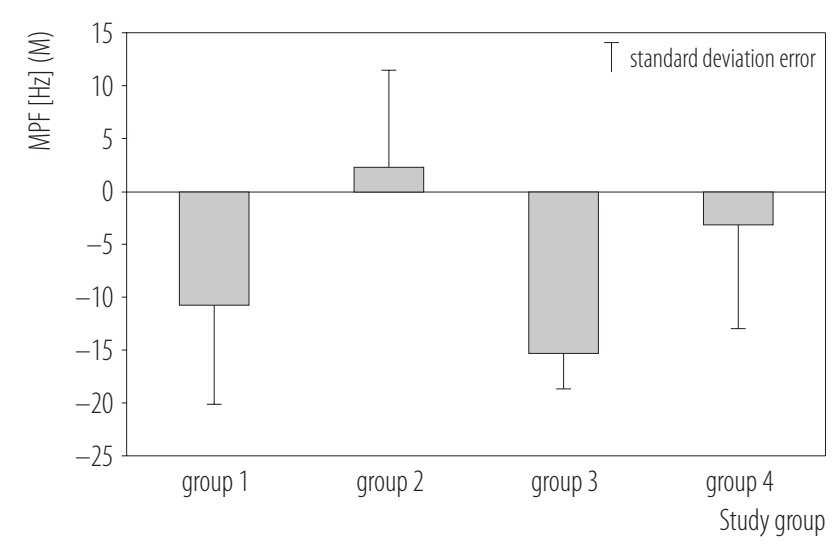

Group: 1 - kneading task, 2 - slicing task, 3 - rolling task, 4 - roasting task.

Fig. 3. Mean power frequency (MPF) in right trapezius of male kitchen workers $(\mathrm{N}=12)$ during various tasks in the kitchen

to the self-administered questionnaire after completion of each task. The self-administered questionnaire uses a 10-point visual-analogue scale. The corresponding mean scores of discomfort at various body regions were tabulated in the Table 2. The result of 10-point visual analogue scale shows that group 3 (the rolling task) workers have the highest pain rate of 8.0 for overall discomfort in various body regions.

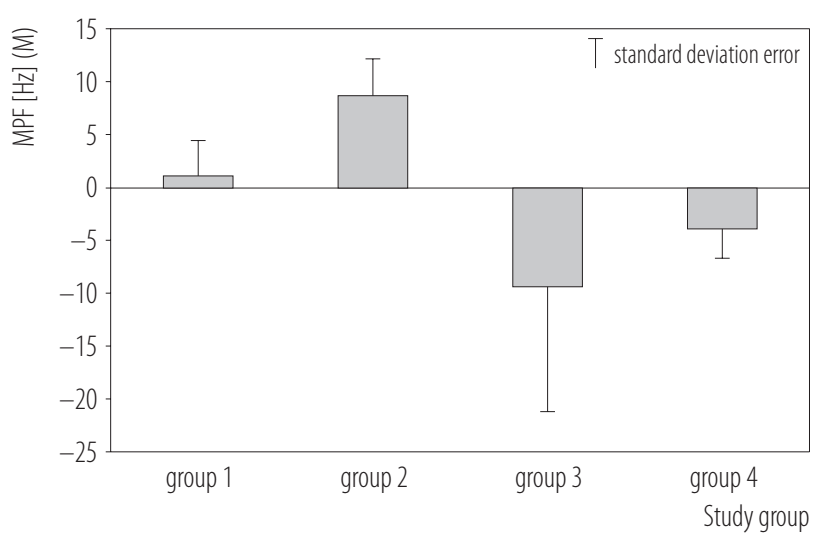

Group: 1 - kneading task, 2 - slicing task, 3 - rolling task, 4 - roasting task.

Fig. 4. Mean power frequency (MPF) in right erector spinae of male kitchen workers $(\mathrm{N}=12)$ during various tasks in the kitchen

\section{DISCUSSION}

Our previous MSDQS indicates that the factors like working hours (not more than $8 \mathrm{~h} /$ day), workspace and working environment were satisfactory. However, the result shows that male kitchen workers possess high MSDs of $67.5 \%$. In particular the highest prevalence of pain or discomfort region is determined as low back region (65.8\%) and shoulder 
Table 2. Discomfort level at various body regions of male kitchen workers $(\mathrm{N}=12)$ during various tasks in accordance with the visual analog 10-point

\begin{tabular}{|c|c|c|c|c|c|}
\hline \multirow{2}{*}{ Muscle/Joint } & \multicolumn{5}{|c|}{$\begin{array}{l}\text { Discomfort level } \\
\text { [pts] } \\
(\mathrm{M})\end{array}$} \\
\hline & $\begin{array}{l}\text { group 1 } \\
(\mathrm{N}=3)\end{array}$ & $\begin{array}{l}\text { group 2 } \\
(\mathrm{N}=3)\end{array}$ & $\begin{array}{l}\text { group 3 } \\
(\mathrm{N}=3)\end{array}$ & $\begin{array}{l}\text { group 4 } \\
(\mathrm{N}=3)\end{array}$ & $\begin{array}{c}\text { total } \\
(\mathrm{N}=12)\end{array}$ \\
\hline Hands (or wrist) & 6.8 & 6.8 & 7.7 & 6.4 & 6.925 \\
\hline Neck & 7.1 & 6.5 & 7.1 & 6.9 & 6.900 \\
\hline Shoulder & 8.2 & 7.6 & 8.9 & 8.5 & 8.300 \\
\hline Low back & 7.2 & 7.1 & 8.3 & 8.3 & 7.725 \\
\hline Legs & 7.0 & 6.4 & 8.0 & 7.9 & 7.325 \\
\hline Overall discomfort & 7.2 & 6.9 & 8.0 & 7.6 & 7.425 \\
\hline
\end{tabular}

M-mean.

Group: 1 - kneading task, 2 - slicing task, 3 - rolling task, 4 - roasting task.

region $(62.3 \%)$ [13,14]. Further to this, in order to determine the muscle fatigue during a given task in the kitchen, the physiological signal (sEMG) study was performed.

De Luca [21] reports that assessing the activity of muscles through sEMG provides insight into the patterns of activation or tension developed in the muscles and reliable means of assessing muscle fatigue in ergonomic studies, respectively. As the phase-1 questionnaire survey (QS) result indicates that low back and shoulder muscle groups play a pre-dominant role in hand intensive work; we have considered only these groups of muscle.

In the sEMG experimental study, MPF difference was used for finding the significant difference of muscle fatigue during, before and after $30 \mathrm{~min}$ of the task. The rolling and roasting task shows a steady MPF decrease among workers and reveals the increase in muscle fatigue. The experimental study results infers that the preparation of Indian flatbread in institutional kitchens leads to both shoulder and low back muscle groups fatigue. Particularly, the right trapezius muscle group shows a significant difference among all tasks except for the slicing task and right erector spinae that show a significant difference between the rolling and roasting task, which indirectly infers that workers adapt an asymmetry loading posture during those tasks. Thus it could contribute to the existence of a significant higher fatigue rate in the right side as compared to the left side of the shoulder.

On the other hand, this could be due to the factor that, all the participants volunteered in this study were the right-hand dominant. In addition, the Indian flatbread preparation task is a complete manual process that is hand-intensive. Hand-intensive and highly repetitive jobs were reported to have most dangerous risk factors in the workplace [22,23]. Chyuan et al. [24] report that $84 \%$ of participants report WMSD with a high prevalence of shoulder (58\%) and lower back/waist (53\%) among hotel restaurant workers in Taiwan.

Similar results have been reported for food service workers with a high prevalence of WMSD at the shoulder of $41.1 \%$ and lower back of $40.1 \%$ [23]. A similar study conducted for professional male kitchen workers in school lunch services [25] shows $72.2 \%$ of low back pain. Results inferred from current studies are well supported by earlier related reports on shoulder and low back discomfort. Furthermore, as reported by Kirkendall [26], muscle fatigue would lead to reduced performance and function. 
The current QS result shows that after 30 min of experiment, workers show less performance. The results based on both experimental and psychophysical parameters provide corroborative evidence to the findings of Balasubramanian et al. [27]. The statistical study, which had been conducted prior to the experimental study, has reported similar results that kitchen workers experience high discomfort at shoulder and low back muscle.

Limitation of this study is the population size and gender participation. In commercial kitchens like institutional kitchens, numbers of experienced workers assigned to each task are lower. This could be due to:

- institute kitchens that represent a small-scale industry,

- workers migration from one task to another, which is habitual,

- kitchen workers who are mostly trained individuals and are not educated by profession.

Secondly, in general, female workers are few in numbers and, on the other hand, they are not intended to perform such heavy tasks, either.

The other risk factors observed for kitchen workers include prolonged standing and excessive force that account for additional discomfort during work. Several studies have investigated both the ergonomic aspects and the productivity aspects to reduce their occupational risk factors and prevent MSD $[28,29]$. This study recommends to prefer ergonomics intervention and proper working procedures that should be formulated for kitchen workers.

\section{CONCLUSIONS}

This study has assessed the effect of highly repetitive working nature like the flatbread task for institutional kitchen workers. Physiological and psychophysical study results are evident that kitchen workers are exposed to the high risk of muscle fatigue in shoulder and low back muscle. In particular, rolling and roasting tasks are repetitive, monotonous, during which workers are affected by excessive force and prolonged standing to a greater extent than in the case of other tasks, which could lead to discomfort at shoulder and low back.

These inferences could be considered during the design of ergonomic intervention on commercial kitchens. Furthermore, this study suggests the following general corrective measures for the purpose of reducing muscle fatigue and discomfort during kitchen work:

- eliminating monotonous working condition,

- optimize work organization by reducing workload caused by excessive force and prolonged standing,

- introducing an appropriate work-rest cycle,

- participatory ergonomic intervention studies may be introduced in the workspace and equipment design,

- volume, frequency and methods of various meals prepared by workers may be systematically evaluated.

\section{ACKNOWLEDGMENTS}

The authors wish to acknowledge all the volunteers involved in this study and would like to express their gratitude to the institution for their invaluable support.

\section{REFERENCES}

1. Pehkonen I, Takala E-P, Ketola R, Viikari-Juntura E, LeinoArjas P, Hopsu L, et al. Evaluation of a participatory ergonomic intervention process in kitchen work. Appl Ergon. 2009; 40(1):115-23, https://doi.org/10.1016/j.apergo.2008.01.006.

2. Ono Y, Nakamura R, Shimaoka M, Hiruta S, Hattori Y, Ichihara $\mathrm{G}$, et al. Epicondylitis among cooks in nursery schools. Occup Environ Med. 1998;55(3):172-9, https://doi. org/10.1136/oem.55.3.172.

3. Collins RM, Janse van Rensburg DC, Patricios JS. Common work-related musculoskeletal strains and injuries. S Afr Fam Pract. 2010;53(3):240-6, https://doi.org/10.1080/20786204.201 1.10874091.

4. Gigstad J. Ergonomic analysis of production cooks at XYZ high school. Menomonie: University of Wisconsin; 2002.

5. Ono Y, Shibata E. Actual conditions of cooking work. Rodo Kagaku (J Sci Lab). 1993;48:196-200. 
6. McPhee C, Lipscomb H. Upper-extremity musculoskeletal symptoms and physical health related quality of life among women employed in poultry processing and other lowwage jobs in Northeastern North Carolina. Am J Ind Med. 2009;52(4):331-40, https://doi.org/10.1002/ajim.20687.

7. Maeda K, Suenaga T, Churei M, Miyao M. A factor-control study on disorders of the back, shoulders, neck and upper limbs of cooks. J Sci Lab. 1986;62(9):435-49.

8. Srinivasan J, Balasubramanian V. Low back pain and muscle fatigue due to road cycling - An sEMG study. J Bodyw Mov Ther. 2007;11(3):260-6, https://doi.org/10.1016/j.jbmt. 2006.08.009.

9. Keyserling WM. Workplace risk factors and occupational musculoskeletal disorders, Part 2: A review of biomechanical and psychophysical research on risk factors associated with upper extremity disorders. Am Ind Hyg Assoc J. 2000;61(2): 231-43, https://doi.org/10.1080/15298660008984532.

10. Habib R, le Zein K, Hojeij S. Hard work at home: Musculoskeletal pain among female homemakers. Ergonomics. 2012; 55(2):201-11, https://doi.org/10.1080/00140139.2011.574157.

11. Basmajian JV. Muscles alive. Their functions revealed by electromyography. Acad Med. 1962;37(8):802.

12. Balasubramanian V, Adalarasu K, Regulapati R. Comparing dynamic and stationary standing postures in an assembly task. Int J Ind Ergon. 2009;39(5):649-54, https:/doi. org/10.1016/j.ergon.2008.10.017.

13. Subramaniam S, Murugesan S. Investigation of work-related musculoskeletal disorders among male kitchen workers in South India. Int J Occup Saf Ergon. 2015;21(4):524-31, https://doi.org/10.1080/10803548.2015.1096063.

14. Shankar S, Shanmugam M, Jayaraman S. Workplace factors and prevalence of low back pain among male commercial kitchen workers. J Back Musculoskelet Rehabil. 2015;28(3):481-8, https://doi.org/10.3233/BMR-140544.

15. Shin H-J, Kim J-Y. Measurement of trunk muscle fatigue during dynamic lifting and lowering as recovery time changes. Int J Ind Ergon. 2007;37(6):545-51, https://doi. org/10.1016/j.ergon.2007.03.006.
16. Van der Hoeven J, van Weerden T, Zwarts M. Long-lasting supernormal conduction velocity after sustained maximal isometric contraction in human muscle. Muscle Nerve. 1993;16(3):312-20, https://doi.org/10.1002/mus.880160312.

17. Park M-Y, Kim J-Y, Shin J-H. Ergonomic design and evaluation of a new VDT workstation chair with keyboard-mouse support. Int J Ind Ergon. 2000;26(5):537-48, https://doi. org/10.1016/S0169-8141(00)00027-5.

18. Balasubramanian V, Prasad GS. Ergonomic assessment of bar cutting process in construction. Int J Ind Syst Eng. 2006; 1(3):321-32, https://doi.org/10.1504/IJISE.2006.009798.

19. Snook SH. Psychophysical acceptability as a constraint in manual working capacity. Ergonomics. 1985;28(1):331-5, https://doi.org/10.1080/00140138508963141.

20. Snook SH, Ciriello VM, Webster BS. Maximum acceptable forces for repetitive wrist extension with a pinch grip. Int J Ind Ergon. 1999;24(6):579-90, https://doi.org/10.1016/ S0169-8141(98)00064-X.

21. De Luca C. Myoelectrical manifestations of localized muscular fatigue in humans. Crit Rev Biomed Eng. 1983;11(4): 251-79.

22. Liu L-W, Wang A-H, Hwang S-L, Lee Y-H, Chen C-Y. Prevalence and risk factors of subjective musculoskeletal symptoms among cooks in Taiwan. J Chin Inst Ind Eng. 2011;28(5):327-35, https://doi.org/10.1080/10170669.2011. 573005 .

23. Chyuan J-Y. Ergonomic assessment of musculoskeletal discomfort among commissary foodservice workers in Taiwan. J Food Bus Res. 2007;10(3):73-86, https://doi.org/10.1300/ J369v10n03_05.

24. Chyuan J-YA, Du C-L, Yeh W-Y, Li C-Y. Musculoskeletal disorders in hotel restaurant workers. Occup Med (Lond). 2004;54(1):55-7, https://doi.org/10.1093/occmed/kqg108.

25. Nagasu M, Sakai K, Ito A, Tomita S, Temmyo Y, Ueno M, et al. Prevalence and risk factors for low back pain among professional cooks working in school lunch services. BMC Public Health. 2007;7(1):171, https://doi.org/10.1186/14712458-7-171. 
26. Kirkendall DT. Mechanisms of peripheral fatigue. Med Sci Sports Exerc. 1990;22(4):444-9, https://doi.org/10.12 49/00005768-199008000-00004.

27. Balasubramanian V, Jagannath M, Adalarasu K. Muscle fatigue based evaluation of bicycle design. Appl Ergon. 2014;45(2):339-45, https://doi.org/10.1016/j.apergo.20 13.04.013.

28. Haukka E, Leino-Arjas P, Solovieva S, Ranta R, ViikariJuntura E, Riihimäki H. Co-occurrence of musculoskeletal pain among female kitchen workers. Int Arch Occup Environ Health. 2006;80(2):141-8, https://doi.org/10.1007/s00 420-006-0113-8.

29. Haukka E, Leino-Arjas P, Viikari-Juntura E, Takala E, Malmivaara A, Hopsu L, et al. A randomised controlled trial on whether a participatory ergonomics intervention could prevent musculoskeletal disorders. Occup Environ Med. 2008;65(12):849-56, https://doi.org/10.1136/oem.2007. 034579 .

This work is available in Open Access model and licensed under a Creative Commons Attribution-NonCommercial 3.0 Poland License - http://creativecommons.org/ licenses/by-nc/3.0/pl/deed.en. 